\title{
Is the chiasm-pituitary corridor size important for achieving gross-total resection during endonasal endoscopic resection of craniopharyngiomas?
}

\author{
Sacit Bulent Omay, MD, ${ }^{1,4}$ João Paulo Almeida, MD, ${ }^{1}$ Yu-Ning Chen, MD, ${ }^{1}$ Sathwik R. Shetty, MD, ${ }^{1}$ \\ Buqing Liang, MD, ${ }^{1}$ Shilei Ni, MD, ${ }^{1}$ Vijay K. Anand, MD, ${ }^{2}$ and Theodore H. Schwartz, MD ${ }^{1-3}$

\begin{abstract}
Departments of ${ }^{1}$ Neurological Surgery, ${ }^{2}$ Otolaryngology, and ${ }^{3}$ Neuroscience, Weill Cornell Medical College, NewYorkPresbyterian Hospital, New York, New York; and ${ }^{2}$ Department of Neurosurgery, Yale School of Medicine, New Haven, Connecticut
\end{abstract}

\begin{abstract}
OBJECTIVE Craniopharyngiomas arise from the pituitary stalk, and in adults they are generally located posterior to the chiasm extending up into the third ventricle. The extended endonasal approach (EEA) can provide an ideal corridor between the bottom of the optic chiasm and the top of the pituitary gland (chiasm-pituitary corridor [CPC]) for their removal. A narrow CPC in patients with a prefixed chiasm and a large tumor extending up and behind the chiasm has been considered a contraindication to EEA, with a high risk of visual deterioration and subtotal resection.

METHODS A database of all patients treated in the authors' center (Weill Cornell Medical College, NewYork-Presbyterian Hospital) between July 2004 and August 2016 was reviewed. Patients with craniopharyngiomas who underwent EEA with the goal of gross-total resection (GTR) were included in the study. Patients with postfixed chiasm or limited available preoperative imaging were excluded. Using preoperative contrast-enhanced T1-weighted sagittal midline MR images, the authors calculated the CPC as well as the distance from the chiasm to the top of the tumor (CTOT). From these numbers, they calculated a ratio of the CPC to the CTOT as a measure of difficulty in removing the tumors through the EEA and called this ratio the corridor index $(\mathrm{Cl})$. The relationship between the $\mathrm{Cl}$ and the ability to achieve GTR and visual outcome were measured.
\end{abstract}

RESULTS Thirty-four patients were included in the study. The mean CPC was $10.1 \mathrm{~mm}$ (range $5.2-19.1 \mathrm{~mm}$ ). The mean CTOT was $12.8 \mathrm{~mm}$ (range $0-28.3 \mathrm{~mm}$ ). The median $\mathrm{Cl}$ was 0.8 ; the $\mathrm{Cl}$ ranged from 0.4 to infinity (for tumors with a CTOT of 0$)$. Thirty-two patients had GTR (94.1\%) and 2 had subtotal resection. The CPC value had no relationship with our ability to achieve GTR and no effect on visual or endocrine outcome.

CONCLUSIONS EEA for craniopharyngioma is generally considered the first-line surgical approach. Although a narrow corridor between the top of the pituitary gland and the bottom of the chiasm may seem to be a relative contraindication to surgery for larger tumors, the authors' data do not bear this out. EEA appears to be a successful technique for the majority of midline craniopharyngiomas.

https://thejns.org/doi/abs/10.3171/2017.6.JNS163188

KEY WORDS craniopharyngioma; optic chiasm; pituitary gland; suprasellar approach; endoscopic endonasal surgery; pituitary surgery

$\mathrm{C}$ RANIOPHARYNIGOMAS represent less than $1 \%$ of all primary central nervous system tumors and arise whe pituitary stalk from the remnants of Rathke's pouch. ${ }^{8}$ They are histologically benign tumors, but their tendency to recur and their location within very close proximity to internal carotid artery (ICA), anterior cerebral arteries (ACAs), pituitary gland, hypothalamus, third ventricle, and the optic apparatus, make them challenging lesions to treat.

Craniopharyngiomas in adults are most commonly located posterior to the chiasm and extend behind the chiasm into the third ventricle. They may present with hydrocephalus, visual loss, pituitary dysfunction, and diabetes insipidus (DI). Surgical management aims to achieve either

ABBREVIATIONS ACA = anterior cerebral artery; $\mathrm{Cl}=$ corridor index; $\mathrm{CPC}=$ chiasm-pituitary corridor; $\mathrm{CTOT}=$ distance from chiasm to top of tumor; $\mathrm{DI}=$ diabetes insipidus; $\mathrm{EEA}=$ extended endonasal approach; GTR = gross-total resection; ICA = internal carotid artery; STR = subtotal resection.

SUBMITTED December 23, 2016. ACCEPTED June 2, 2017.

INCLUDE WHEN CITING Published online November 24, 2017; DOI: 10.3171/2017.6.JNS163188. 
gross-total resection (GTR) or subtotal resection (STR), with STR being coupled with adjuvant radiation therapy. The latter strategy has gained some favor in recent years due to reduced morbidity and equivalent progression-free and overall survival, ${ }^{1,35}$ and there has been recent progress in use of targeted therapies against BRAF-mutated craniopharyngiomas. ${ }^{3}$ Nevertheless, surgery is still the treatment method that offers the highest chance of cure, if GTR can be achieved. ${ }^{27}$

There are several transcranial routes that can be used for the resection of these lesions, including interhemispheric, frontobasal, or frontotemporal with or without orbitozygomatic modifications, ${ }^{1}$ but transcranial approaches require varying degrees of brain retraction and manipulation of neurovascular structures. ${ }^{37}$

The extended endonasal approach (EEA) has been introduced as an alternative to craniotomy for craniopharyngiomas extending up into the suprasellar cistern and third ventricle. This approach provides a clear surgical view inferior and posterior to the chiasm into the third ventricle, which may promote higher rates of resection with better visual outcomes and sustained quality of life. . $^{5,6,19,21,28,29}$

EEA can provide an ideal corridor between the bottom of the optic chiasm and the top of the pituitary gland (chiasm-pituitary corridor [CPC]) for removal of craniopharyngiomas. However, a narrow $\mathrm{CPC}$ with a large tumor extending up and behind the chiasm has been considered a contraindication to EEA, with a high risk of visual deterioration and consequent STR. ${ }^{25}$ Patients with prefixed chiasms will tend to have a narrow CPC, while those with postfixed chiasms will have a large CPC. Classifications based on the location of craniopharyngiomas with respect to the infundibulum have been used to provide guidance for approach strategies. ${ }^{17}$ We retrospectively reviewed our series of craniopharyngiomas resected using EEA by the senior author (T.H.S.) to answer the question whether a narrow CPC along with a high-rising tumor above the level of the chiasm can prevent GTR and impact visual outcome.

\section{Methods}

A database of all patients treated in our center (Weill Cornell Medical College, NewYork-Presbyterian Hospital) between July 2004 and August 2016 was reviewed. Patients with craniopharyngiomas who underwent EEA with the goal of GTR were included in the study. The patients excluded were elderly or frail patients who might not tolerate an aggressive operation, patients in whom pituitary function needed to be preserved, children with hypothalamic invasion, and patients with previously operated/radiated tumors with cyst growth that required drainage for optic chiasmal decompression. No patient was excluded because the chiasm location was thought to limit our approach, since this would bias the results. Patients with a postfixed chiasm were excluded, since the tumor is in front of the chiasm and the corridor between the chiasm and gland is not a factor in removing the tumor. Patients with limited available preoperative imaging were also excluded. At Weill Cornell, all of our surgeries are performed through the corridor from the top of the pituitary gland to the bottom of the chiasm; we do not work above the chiasm to enter the third ventricle due to the presence of the anterior communicating artery complex and its blood supply to the chiasm. Using preoperative contrast-enhanced T1-weighted sagittal midline MR images, we measured this chiasm-pituitary corridor (CPC) as the distance between the top of the pituitary gland and the bottom of the optic chiasm. We also measured the distance from the top of chiasm to the top of the tumor (solid or cystic). To ensure that the measurements would not be affected by anatomical differences, we drew a line connecting the top of the chiasm to the most inferior point of the splenium and measured the perpendicular distance from the most superior aspect of the tumor to this line (CTOT) (Figs. 1 and 2). This factor is also critical because the greater the amount of the tumor that sits above the chiasm, the harder it will be to remove the tumor through the CPC corridor. From these 2 numbers we then calculated a ratio of the CPC to the CTOT as a measure of the difficulty in removing the tumors through the EEA and called this ratio the corridor index (CI). The relationship between the CI and the ability to achieve GTR as well as endocrine and visual outcomes were analyzed to determine if these factors are critical to the success of the surgery.

Endocrine outcome was defined as the presence of any new endocrine deficiency including anterior pituitary hormones, desmopressin, and obesity, versus no change relative to preoperative status.

Visual outcome was defined as stable or improved versus worsened visual acuity and/or visual fields.

\section{Surgery}

The EEA transtuberculum transplanum approach has been previously described in detail by various groups. , $7,16,21^{-1}$ In brief, a lumbar drain is placed and $0.25 \mathrm{ml}$ of $10 \%$ fluorescein (AK-FLUOR, Akorn) is injected slowly into the intrathecal space after being mixed with $10 \mathrm{ml}$ of CSF. ${ }^{30}$ A vascularized nasoseptal flap is raised after lateralization of the middle turbinates and set aside in the nasopharynx for subsequent reconstruction. The inferior two-thirds of the left superior turbinate is often removed to create space for the endoscope. The transplanum transtuberculum approach is performed to expose the top of the pituitary gland and the tuberculum sellae is opened to expose the top of the optic chiasm. The superior intercavernous sinus is coagulated and resected along with the diaphragma sellae. The CPC corridor is cleared free of arachnoid, the superior hypophyseal arteries are swept laterally, and the tumor and pituitary stalk are dissected free of the arachnoid (Fig. 3). The tumor is internally debulked; the capsule is then dissected from the surrounding neurovascular structures and removed. Angled endoscopes and instruments are valuable in visualizing the uppermost aspect of tumors extending toward the roof of the third ventricle from below the chiasm. The stalk is preserved as long as possible and is only resected at the end of the operation if required to achieve GTR. ${ }^{31}$ The superior hypophyseal arteries are preserved unless they feed a stalk infiltrated with tumor that is to be resected. If the tumor extends into the sella, the top of the pituitary gland is also removed to ensure complete resection. The closure is performed with a fascia 


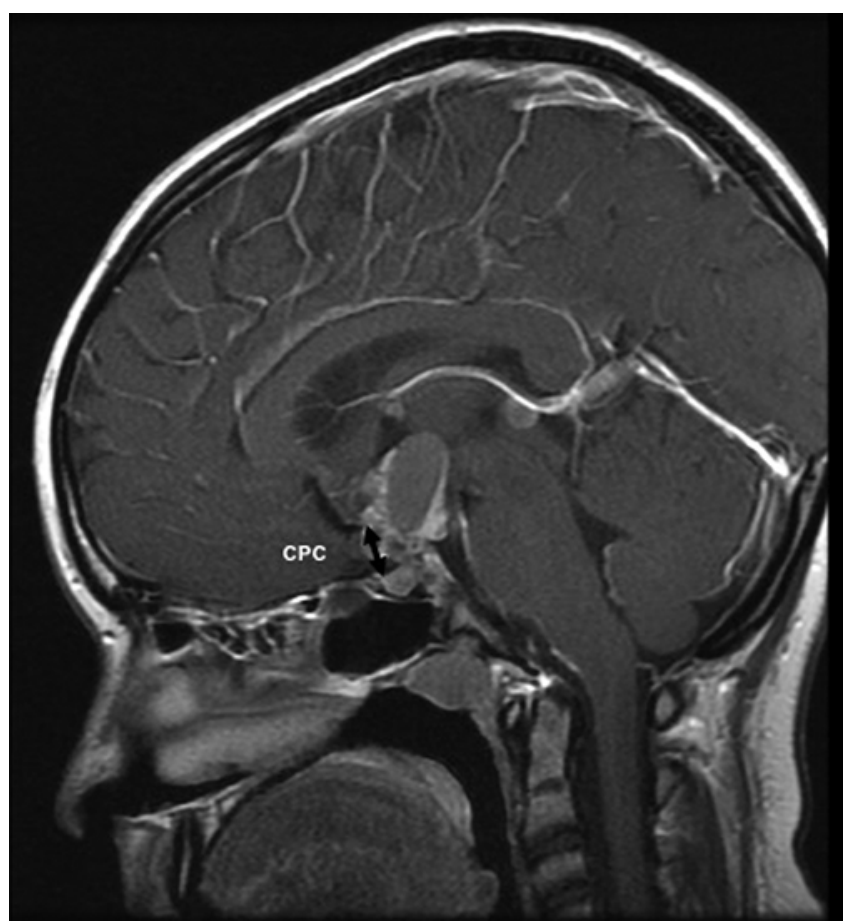

FIG. 1. Measurement of chiasm-pituitary corridor (CPC, double-headed arrow) on a preoperative contrast-enhanced T1-weighted sagittal midline MR image. The CPC was defined as the distance between the top of the pituitary gland and the bottom of the optic chiasm.

lata onlay with Medpore wedged into the defect to achieve a gasket-seal closure, and covered with a nasoseptal flap and then Duraseal (Integra). ${ }^{10,22,26}$

\section{Results}

During the study period, 62 patients with craniopharyngiomas were operated upon using an EEA. The goal was GTR in 41 cases. Reasons for not pursing a GTR were previous surgery and/or radiation (in 8 cases), pediatric age with likely hypothalamic invasion (in 2), goal of cyst drainage and biopsy in an attempt to preserve pituitary function (in 4), and goal of decompression of the optic apparatus (in 7). Patients with postfixed chiasm (1 patient) or limited available preoperative imaging (6 patients) were excluded. Thirty-four patients were included in the study.

The mean CPC was $10.1 \mathrm{~mm}$ (range 5.2-19.1 mm). The mean CTOT was $12.8 \mathrm{~mm}$ (range $0-28.3 \mathrm{~mm}$ ). The median CI was 0.8 , and the $\mathrm{CI}$ ranged from 0.4 to infinity (for tumors with a CTOT of 0 ). The median was chosen since the upper limit was infinity. Thirty-two patients had GTR and 2 had STR (CIs 1.1 and 0.6). GTR was achieved in 95\% of patients. In the 2 patients with STR, the locations of residual tumor were ICA branches and the pituitary stalk $(\mathrm{n}=1)$ and "diffuse" due to prior operations and radiotherapy $(\mathrm{n}=1)$. The CPC and CI values had no statistically significant relationship with our ability to achieve GTR. New anterior pituitary dysfunction occurred in 44\% of patients and new posterior pituitary dysfunction (DI) occurred in $29 \%$, with a total new endocrinopathy rate of $44 \%$. The presence of new endocrinopathy did not correlate with $\mathrm{CI}$ ratio. The visual outcome was stable or im-

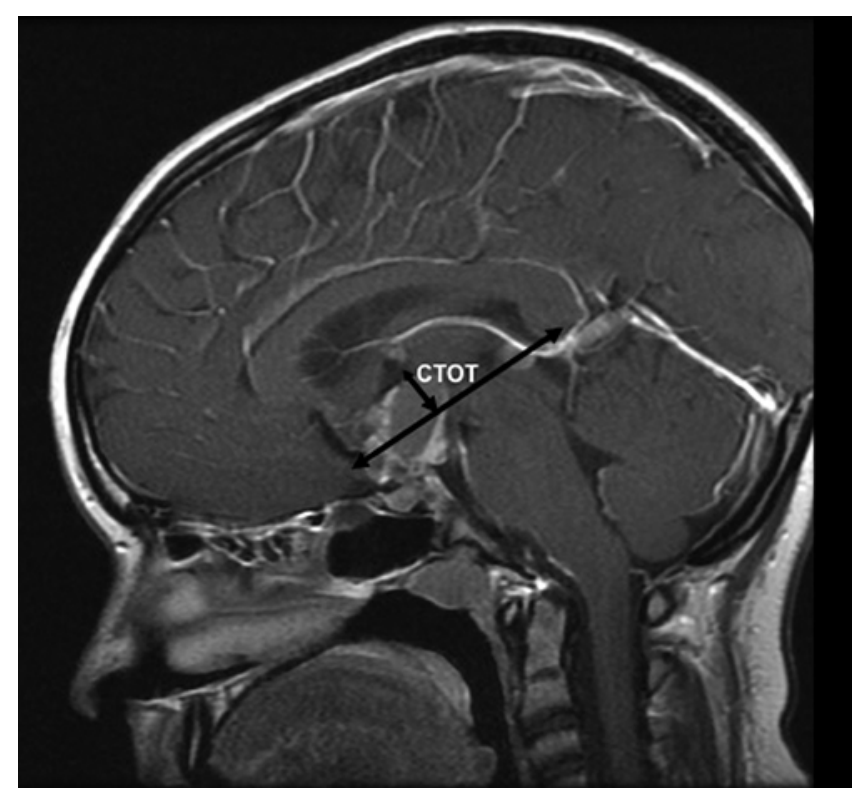

FIG. 2. Measurement of the distance from the chiasm to the top of the tumor (CTOT) on a preoperative contrast-enhanced T1-weighted sagittal midline MR image. The CTOT was measured as the length of a perpendicular line (short double-headed arrow) from the most superior aspect of the tumor to a line connecting the top of the chiasm to the most inferior point of the splenium (long double-headed arrow).

proved in $94 \%$ of patients and worse in $6 \%$, which also did not correlate with the CI number.

\section{Discussion}

The major finding of this report is that the size of the surgical corridor between the bottom of the optic chiasm and the top of the pituitary gland does not impact the likelihood of GTR in patients undergoing craniopharyngioma resection via EEA. Moreover, the amount of tumor extending up into the third ventricle above and behind the chiasm, even relative to the size of surgical corridor, is not a factor in GTR. Likewise, the size of this corridor has no effect on either visual or endocrine outcome. Our results of $6 \%$ visual worsening, $29 \%$ new DI, and $44 \%$ new hypopituitarism are better than the published transcranial results of $11.3 \%$ visual worsening, $54.8 \%$ new DI, and $48.1 \%$ new hypopituitarism, and are comparable to transcranial and transsphenoidal results of $5.6 \%$ visual worsening and 49.8\% new hypopituitarism. ${ }^{19,34}$ Although this could be considered a "negative" study, the results are important as they impact surgical decision making and case selection and serve to debunk a false contraindication to EEA for craniopharyngioma resection.

Craniopharyngioma treatment remains a controversial area of neurosurgical therapy. One area of continued discussion is the debate over radical versus conservative surgery. Although there is no Level I or Level II evidence favoring one or the other approach, retrospective literature review supports the conclusion that GTR provides an improved rate of progression-free survival, ${ }^{12,13,27,36}$ with the exception of cases involving tumors that invade the hypothalamus. ${ }^{9,27}$ A second area of debate is the preferred sur- 


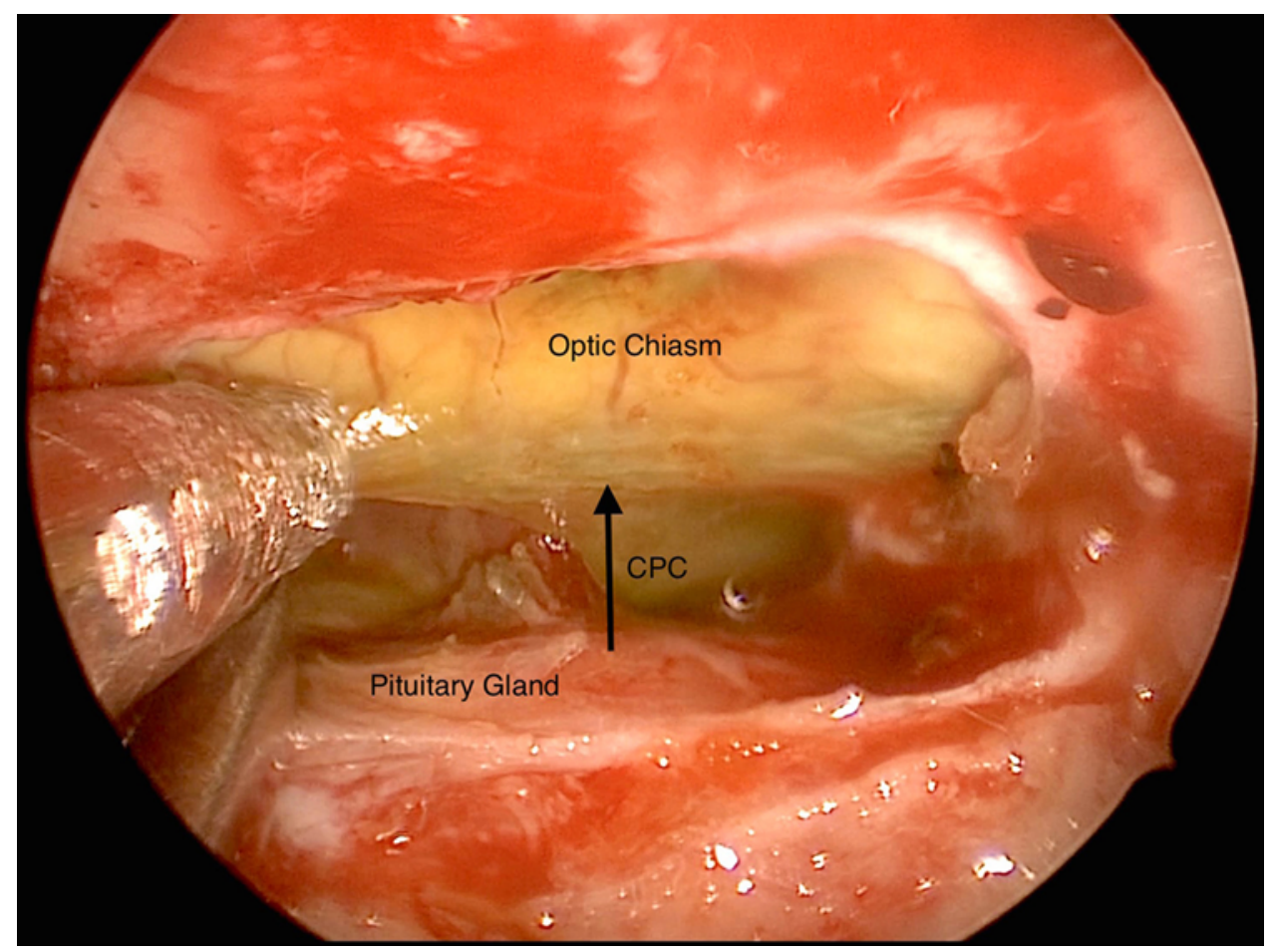

FIG. 3. Intraoperative image obtained during an EEA for a craniopharyngioma showing the pituitary gland, optic chiasm, and CPC. The full length of the arrow is the measurement of the CPC. Figure is available in color online only.

gical approach, transcranial versus EEA. Until recently, transsphenoidal approaches have been thought to be only suitable for treatment of sellar craniopharyngiomas, and tumors with suprasellar or intraventricular extension were thought to require transcranial approaches. Traditional transcranial approaches generally entail brain retraction and manipulation of cerebrovascular structures that lie between the surgeon and the pathology. ${ }^{15,23,37}$ As the technology and experience with EEA improved, the limitations of EEA diminished and the applicability to midline craniopharyngiomas with suprasellar and intraventricular extension increased. Recent literature suggests that the results of EEA for craniopharyngioma resection are superior to transcranial approaches with respect to extent of resection and endocrine and visual outcomes. $5,6,8,11,14,19-21,28,29$ The Achilles' heel of EEA, the CSF leak rate, has also dramatically diminished with use of the vascularized nasoseptal flap and multilayer reconstruction. . $^{2,24}$

In this paper, we investigate another potential anatomical limitation to EEA, particularly for those craniopharyngiomas with extension behind the chiasm into the third ventricle. A narrow CPC with a large tumor extending up and behind the chiasm has been considered a contraindication to EEA, with a high risk of visual deterioration and consequent STR. ${ }^{25}$ Our review reveals that neither a narrow corridor nor a high-rising tumor behind the chiasm should be considered a contraindication for craniopharyngiomas. Although pituitary transposition has been described to increase the working corridor into the suprasellar cistern, this maneuver really only increases the view to the interpeduncular cistern, and it increases the rate of pituitary dysfunction and the rate of CSF leak. ${ }^{18}$ For this reason, we do not recommend this maneuver and prefer using an above-and-below approach or extradural posterior clinoidectomy. ${ }^{32,33} \mathrm{We}$ find that gentle upward pressure on the chiasm and downward pressure on the top of the pituitary gland can safely enlarge this corridor for removal of even craniopharyngiomas that extend up to the roof of the third ventricle. Our findings hold true regardless of whether the tumor is cystic or solid. Although one might think cystic tumors would be easier to remove than solid tumors, the opposite is the case. We find that the cystic tumors are slightly more difficult to remove completely than the solid tumors because the thin cyst wall sticks to the third ventricle roof more so than the solid tumor, which is more easily removed in one piece. The use of angled endoscopes and instruments is critically important to safely visualizing the superior extent of the tumor under the chiasm. Preservation of superior hypothalamic perforators to the chiasm is also important for preserving vision.

\section{Conclusions}

The location of the chiasm (prefixed or postfixed), the size of the corridor between the top of the pituitary gland and the bottom of the chiasm, or the superior extent of the tumor should not be considered an absolute contraindication to EEA for craniopharyngioma. Careful case selection and experience will always dictate the preferred approach in the hands of any given surgeon.

\section{References}

1. Alli S, Isik S, Rutka JT: Microsurgical removal of craniopha- 
ryngioma: endoscopic and transcranial techniques for complication avoidance. J Neurooncol 130:299-307, 2016

2. Banu MA, Guerrero-Maldonado A, McCrea HJ, GarciaNavarro V, Souweidane MM, Anand VK, et al: Impact of skull base development on endonasal endoscopic surgical corridors. J Neurosurg Pediatr 13:155-169, 2014

3. Brastianos PK, Shankar GM, Gill CM, Taylor-Weiner A, Nayyar N, Panka DJ, et al: Dramatic response of BRAF V600E mutant papillary craniopharyngioma to targeted therapy. J Natl Cancer Inst 108:108, 2015

4. Cavallo LM, de Divitiis O, Aydin S, Messina A, Esposito F, Iaconetta $\mathrm{G}$, et al: Extended endoscopic endonasal transsphenoidal approach to the suprasellar area: anatomic considerations-part 1. Neurosurgery 62 (6 Suppl 3):1202-1212, 2008

5. Cavallo LM, Prevedello DM, Solari D, Gardner PA, Esposito F, Snyderman CH, et al: Extended endoscopic endonasal transsphenoidal approach for residual or recurrent craniopharyngiomas. J Neurosurg 111:578-589, 2009

6. Conger AR, Lucas J, Zada G, Schwartz TH, Cohen-Gadol AA: Endoscopic extended transsphenoidal resection of craniopharyngiomas: nuances of neurosurgical technique. Neurosurg Focus 37(4):E10, 2014

7. de Divitiis E, Cavallo LM, Cappabianca P, Esposito F: Extended endoscopic endonasal transsphenoidal approach for the removal of suprasellar tumors: Part 2. Neurosurgery 60:46-59, 2007

8. Dhandapani S, Singh H, Negm HM, Cohen S, Souweidane MM, Greenfield JP, et al: Endonasal endoscopic reoperation for residual or recurrent craniopharyngiomas. J Neurosurg 126:418-430, 2017

9. Elowe-Gruau E, Beltrand J, Brauner R, Pinto G, SamaraBoustani D, Thalassinos C, et al: Childhood craniopharyngioma: hypothalamus-sparing surgery decreases the risk of obesity. J Clin Endocrinol Metab 98:2376-2382, 2013

10. Garcia-Navarro V, Anand VK, Schwartz TH: Gasket seal closure for extended endonasal endoscopic skull base surgery: efficacy in a large case series. World Neurosurg 80:563-568, 2013

11. Gardner PA, Kassam AB, Snyderman CH, Carrau RL, Mintz $\mathrm{AH}$, Grahovac S, et al: Outcomes following endoscopic, expanded endonasal resection of suprasellar craniopharyngiomas: a case series. J Neurosurg 109:6-16, 2008

12. Gautier A, Godbout A, Grosheny C, Tejedor I, Coudert M, Courtillot C, et al: Markers of recurrence and long-term morbidity in craniopharyngioma: a systematic analysis of 171 patients. J Clin Endocrinol Metab 97:1258-1267, 2012

13. Hofmann BM, Höllig A, Strauss C, Buslei R, Buchfelder M, Fahlbusch R: Results after treatment of craniopharyngiomas: further experiences with 73 patients since 1997. J Neurosurg 116:373-384, 2012

14. Jane JA Jr, Kiehna E, Payne SC, Early SV, Laws ER Jr: Early outcomes of endoscopic transsphenoidal surgery for adult craniopharyngiomas. Neurosurg Focus 28(4):E9, 2010

15. Karavitaki N, Cudlip S, Adams CB, Wass JA: Craniopharyngiomas. Endocr Rev 27:371-397, 2006

16. Kassam A, Snyderman CH, Mintz A, Gardner P, Carrau RL: Expanded endonasal approach: the rostrocaudal axis. Part I. Crista galli to the sella turcica. Neurosurg Focus 19(1):E3, 2005

17. Kassam AB, Gardner PA, Snyderman CH, Carrau RL, Mintz $\mathrm{AH}$, Prevedello DM: Expanded endonasal approach, a fully endoscopic transnasal approach for the resection of midline suprasellar craniopharyngiomas: a new classification based on the infundibulum. J Neurosurg 108:715-728, 2008

18. Kassam AB, Prevedello DM, Thomas A, Gardner P, Mintz A, Snyderman C, et al: Endoscopic endonasal pituitary transposition for a transdorsum sellae approach to the interpeduncular cistern. Neurosurgery 62 (3 Suppl 1):57-74, 2008
19. Komotar RJ, Starke RM, Raper DM, Anand VK, Schwartz TH: Endoscopic endonasal compared with microscopic transsphenoidal and open transcranial resection of craniopharyngiomas. World Neurosurg 77:329-341, 2012

20. Koutourousiou M, Gardner PA, Fernandez-Miranda JC, Tyler-Kabara EC, Wang EW, Snyderman CH: Endoscopic endonasal surgery for craniopharyngiomas: surgical outcome in 64 patients. J Neurosurg 119:1194-1207, 2013

21. Laufer I, Anand VK, Schwartz TH: Endoscopic, endonasal extended transsphenoidal, transplanum transtuberculum approach for resection of suprasellar lesions. J Neurosurg 106:400-406, 2007

22. Leng LZ, Brown S, Anand VK, Schwartz TH: "Gasket-seal" watertight closure in minimal-access endoscopic cranial base surgery. Neurosurgery 62 (5 Suppl 2):ONSE342-ONSE343, 2008

23. Leng LZ, Greenfield JP, Souweidane MM, Anand VK, Schwartz TH: Endoscopic, endonasal resection of craniopharyngiomas: analysis of outcome including extent of resection, cerebrospinal fluid leak, return to preoperative productivity, and body mass index. Neurosurgery 70:110124, 2012

24. Mascarenhas L, Moshel YA, Bayad F, Szentirmai O, Salek AA, Leng LZ, et al: The transplanum transtuberculum approaches for suprasellar and sellar-suprasellar lesions: avoidance of cerebrospinal fluid leak and lessons learned. World Neurosurg 82:186-195, 2014

25. Matsuo T, Kamada K, Izumo T, Nagata I: Indication and limitations of endoscopic extended transsphenoidal surgery for craniopharyngioma. Neurol Med Chir (Tokyo) 54:974-982, 2014

26. McCoul ED, Anand VK, Singh A, Nyquist GG, Schaberg MR, Schwartz TH: Long-term effectiveness of a reconstructive protocol using the nasoseptal flap after endoscopic skull base surgery. World Neurosurg 81:136-143, 2014

27. Mehta GU, Jane J Jr, Oldfield EH: Complete resection of craniopharyngiomas, in Evans JJ, Kenning TJ (eds): Craniopharyngiomas, ed 1. Cambridge, MA: Academic Press, 2016

28. Moussazadeh N, Prabhu V, Bander ED, Cusic RC, Tsiouris AJ, Anand VK, et al: Endoscopic endonasal versus open transcranial resection of craniopharyngiomas: a casematched single-institution analysis. Neurosurg Focus 41(6):E7, 2016

29. Patel KS, Raza SM, McCoul ED, Patrona A, Greenfield JP, Souweidane MM, et al: Long-term quality of life after endonasal endoscopic resection of adult craniopharyngiomas. J Neurosurg 123:571-580, 2015

30. Placantonakis DG, Tabaee A, Anand VK, Hiltzik D, Schwartz TH: Safety of low-dose intrathecal fluorescein in endoscopic cranial base surgery. Neurosurgery 61 (3 Suppl):161-166, 2007

31. Prabhu V, Anand VK, Schwartz TH: Preservation of pituitary function after endonasal craniopharyngioma surgery: case report and review of the literature. Cureus 7:e305, 2015

32. Silva D, Attia M, Kandasamy J, Alimi M, Anand VK, Schwartz TH: Endoscopic endonasal posterior clinoidectomy. Surg Neurol Int 3:64, 2012

33. Silva D, Attia M, Kandasamy J, Alimi M, Anand VK, Schwartz TH: Endoscopic endonasal transsphenoidal "above and below" approach to the retroinfundibular area and interpeduncular cistern-cadaveric study and case illustrations. World Neurosurg 81:374-384, 2014

34. Sughrue ME, Yang I, Kane AJ, Fang S, Clark AJ, Aranda D, et al: Endocrinologic, neurologic, and visual morbidity after treatment for craniopharyngioma. J Neurooncol 101:463476, 2011

35. Yang I, Sughrue ME, Rutkowski MJ, Kaur R, Ivan ME, Aranda D, et al: Craniopharyngioma: a comparison of tumor 
control with various treatment strategies. Neurosurg Focus 28(4):E5, 2010

36. Yaşargil MG, Curcic M, Kis M, Siegenthaler G, Teddy PJ, Roth P: Total removal of craniopharyngiomas. Approaches and long-term results in 144 patients. J Neurosurg 73:3-11, 1990

37. Zacharia BE, Amine M, Anand V, Schwartz TH: Endoscopic endonasal management of craniopharyngioma. Otolaryngol Clin North Am 49:201-212, 2016

\section{Disclosures}

Dr. Schwartz reports direct stock ownership in VisionSense.

\section{Author Contributions}

Conception and design: Schwartz, Omay, Anand. Acquisition of data: Omay, Almeida, Chen. Analysis and interpretation of data: Schwartz, Omay, Shetty, Liang, Ni. Drafting the article: Omay, Almeida, Chen. Critically revising the article: Schwartz. Reviewed submitted version of manuscript: Schwartz, Omay. Approved the final version of the manuscript on behalf of all authors: Schwartz. Statistical analysis: Omay. Administrative/technical/material support: Schwartz. Study supervision: Schwartz, Anand.

\section{Correspondence}

Theodore H. Schwartz, Department of Neurological Surgery, Weill Cornell Medical College, 525 East 68th St., Box 99, New York, NY 10065. email: schwarh@med.cornell.edu. 